\title{
Bioavailability of the flavonol quercetin in cows after intraruminal application of quercetin aglycone and rutin
}

\author{
L. M. Berger, ${ }^{* 1}$ S. Wein, ${ }^{*}$ R. Blank, ${ }^{\star}$ C. C. Metges, $†$ and S. Wolffram ${ }^{\star}$ \\ *Institute of Animal Nutrition and Physiology, Christian-Albrechts-University of Kiel, 24118 Kiel, Germany \\ †Research Unit Nutrition Physiology, Leibniz Institute for Farm Animal Biology (FBN), 18196 Dummerstorf, Germany
}

\begin{abstract}
The bioavailability of quercetin has been intensively investigated in monogastric species, but knowledge about its bioavailability in ruminants does not exist. Thus, the aim of the present study was to determine the bioavailability of quercetin in nonlactating cows equipped with indwelling catheters placed in one jugular vein after intraruminal and additionally after i.v. application, respectively. Quercetin was administered intraruminally in equimolar amounts, either in the aglycone form or as its glucorhamnoside rutin, each at 2 dosages [10 and $50 \mathrm{mg}$ of quercetin $/ \mathrm{kg}$ of body weight $(\mathrm{BW})]$. In a second trial, $0.8 \mathrm{mg}$ of quercetin aglycone $/ \mathrm{kg}$ of $\mathrm{BW}$ was applied i.v. Blood samples were drawn $0.5,1,1.5,2,2.5,3,4,6,8,12$, and $24 \mathrm{~h}$ after intraruminal application and every $5 \mathrm{~min}$ (first hour), every $10 \mathrm{~min}$ (second hour), and at 3 and $6 \mathrm{~h}$ after i.v. bolus application, respectively. Quercetin and quercetin metabolites with an intact flavonol structure (isorhamnetin, tamarixetin, and kaempferol) in plasma samples were analyzed by HPLC with fluorescence detection. After intraruminal application of quercetin and rutin, respectively, quercetin and its methylated (isorhamnetin, tamarixetin) and dehydroxylated (kaempferol) derivatives were present in plasma mainly as conjugated forms, whereas free quercetin and its derivatives were scarcely detected. For rutin, the relative bioavailability of total flavonols (sum of conjugated and nonconjugated quercetin and its conjugated and nonconjugated derivatives after intake of $50 \mathrm{mg} / \mathrm{kg}$ of BW) was $767.3 \%$ compared with quercetin aglycone $(100 \%)$. Absolute bioavailability of total flavonols was only 0.1 and $0.5 \%$ after quercetin aglycone and rutin applications, respectively. Our data demonstrate that bioavailability of quercetin from rutin is substantially higher compared with that from quercetin aglycone in cows after intraruminal (or oral) application, unlike in monogastric species.
\end{abstract}

Received February 16, 2012.

Accepted May 14, 2012.

${ }^{1}$ Corresponding author: berger@aninut.uni-kiel.de
Key words: quercetin, rutin, bioavailability, cow

\section{INTRODUCTION}

Flavonoids belong to a large group of natural, plantderived, polyphenolic compounds and they are widely distributed in feed and feed plants (Besle et al., 2010). Therefore, they are ingested by animals in various amounts as part of their regular diet, but concentrations in feed plants are rather low. Besle et al. (2010) investigated the total polyphenol content of various forages ingested by dairy cows. Although grassland pasture had the highest total polyphenol content $(35.3 \mathrm{~g} / \mathrm{kg}$ of DM) in that study, the lowest value was reported for maize silage $(3.7 \mathrm{~g} / \mathrm{kg}$ of $\mathrm{DM})$. With respect to quercetin, the same authors reported values of $0.68 \mathrm{~g} / \mathrm{kg}$ of DM, for example, in ryegrass silage, whereas quercetin in grassland pasture or maize silage was not quantified in their analysis (Besle et al., 2010). In addition, many plant-derived extracts, which contain considerable amounts of various flavonoids, are commercially offered for animal nutrition with the claim of enhancing or stabilizing animal performance and health.

Flavonoids exert various effects on mammalian cells and tissues. In this context, many flavonoids are well known for their antioxidative capabilities in vitro (Bors et al., 1990; Morand et al., 1998). Furthermore, they influence the expression of numerous genes as well as the activity of several key enzymes (Middleton et al., 2000; Williamson and Manach, 2005). To this end, it has been shown in monogastric species that the expression and activities of enzymes involved in lipid and carbohydrate metabolism (Gasparin et al., 2003; Kobayashi et al., 2010) can be influenced by flavonoids.

Although the majority of data on biological effects are derived from cell culture studies and experiments in monogastric species, it can be hypothesized that flavonoids, if present in the circulation, might have similar effects in ruminants. In this context, flavonoids administered in the phase of early lactation in dairy cows might be of special interest due to metabolic disorders such as fatty liver disease and ketosis that often occur in this phase (Duske et al., 2009; Hammon et al., 2009). 
Based on the substitution pattern of the ring structure, flavonoids are usually divided into 9 main classes, with quercetin belonging to the class of flavonols. Flavonols are characterized by the substitution of a hydroxyl group at position C-3 and a double bond between C-2 and C-3 (Bors et al., 1990; Figure 1). Quercetin is one of the most abundant flavonoids present in plants (Kühnau, 1976). In plants and most plant-derived feed, flavonoids are mainly present as glycosides with the aglycone linked to a variable sugar moiety by a $\beta$-glycosidic bond (Kühnau, 1976), mainly at the 3-position of the C-ring (Crozier et al., 2006). Among the various quercetin glycosides, the glucorhamnoside rutin is a relatively cheap and important source for quercetin and therefore has been investigated in many studies. Although not frequently used as feed plant, buckwheat (Fagopyrum esculentum) contains considerable amounts of rutin (55 g/ $\mathrm{kg}$ of DM; Broudiscou et al., 2000).

To exert any biological effect, however, quercetin, its active metabolites, or both, must be systemically available. In this context, the bioavailability of quercetin has been investigated in different monogastric species (e.g., rat, pig, human, and dog; Manach et al., 1997; Ader et al., 2000; Egert et al., 2008; Reinboth et al., 2010). In monogastric species, quercetin monoglucosides are deglycosylated in the small intestine by intestinal glucosidases to liberate the aglycone, which can then be absorbed passively (Gee et al., 2000; Wolffram et al., 2002). Quercetin glycosides other than monoglucosides such as rutin cannot be absorbed until they have reached the large intestine, where hydrolysis of glycosides by microbial $\alpha$-rhamnosidases and $\beta$-glucosidases releases the aglycone (Bokkenheuser et al., 1987; Cermak et al., 2003). In monogastric species, it is generally accepted that the sugar moiety of quercetin glycosides is a ma-

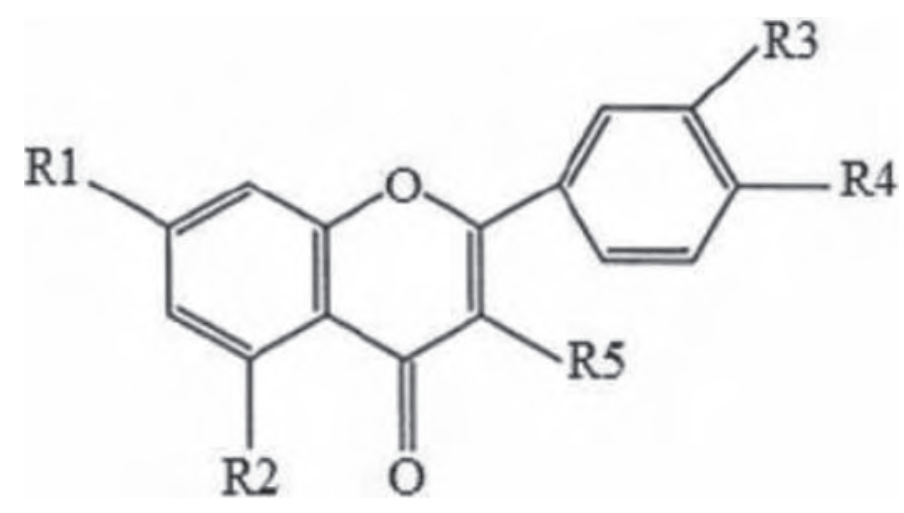

Figure 1. Molecular structure of flavonols used in this study; quercetin: R1, R2, R3, R4, and $\mathrm{R} 5=\mathrm{OH}$; rutin: $\mathrm{R} 1, \mathrm{R} 2, \mathrm{R} 3$, and $\mathrm{R} 4=$ $\mathrm{OH}, \mathrm{R} 5=$ glucorhamnoside; kaempferol: R1, R2, R4, and $\mathrm{R} 5=\mathrm{OH}$, $\mathrm{R} 3=\mathrm{H}$; isorhamnetin: $\mathrm{R} 1, \mathrm{R} 2, \mathrm{R} 4$, and $\mathrm{R} 5=\mathrm{OH}, \mathrm{R} 3=\mathrm{OCH}_{3}$; tamarixetin: $\mathrm{R} 1, \mathrm{R} 2, \mathrm{R} 3$, and $\mathrm{R} 5=\mathrm{OH}, \mathrm{R} 4=\mathrm{OCH}_{3}$. jor determinant of the oral bioavailability of quercetin (Hollman et al., 1999; Cermak et al., 2003). Thus, in monogastrics, the oral bioavailability from quercetin applied as aglycone is higher than that of rutin (Manach et al., 1997; Erlund et al., 2000; Cermak et al., 2003). After absorption, quercetin and its metabolites with an intact flavonol structure (isorhamnetin, tamarixetin, and kaempferol) are mainly present in blood plasma as glucoronidated and sulfated derivatives (Manach et al., 1997; Ader et al., 2000; Erlund et al., 2000).

The bioavailability of quercetin in ruminants has not been investigated to date. In vitro studies on the degradation of various flavonoids by the fecal and ruminal flora have found a more or less complete microbial degradation of quercetin and quercetin glycosides (Blaut et al., 2003; Lin et al., 2003; Labib et al., 2004). Because quercetin appears to be mainly absorbed from the small intestine (Gee et al., 2000; Cermak et al., 2003), it can be assumed that the bioavailability of quercetin might be lower in ruminants compared with monogastric species because of extensive fermentation in the rumen after oral intake.

The aim of the present study was to investigate the absolute and relative bioavailability of quercetin after i.v. application of the flavonol or after intraruminal administration, respectively, of either quercetin aglycone or rutin at 2 dosages in nonlactating dairy cows.

\section{MATERIALS AND METHODS}

\section{Animals and Diet}

For the experiments, 5 ruminally fistulated nonlactating cows (Deutsches Schwarzbuntes Niederungsrind) with an average BW of $479 \pm 32 \mathrm{~kg}$ were used in a crossover design with a 2-d wash-out period between each application. Animals were surgically equipped with an indwelling catheter (WVI Jugularis Teflon catheter, C. Walter, Baruth/Mark, Germany) in one jugular vein and were fed a maintenance ration consisting of $1.5 \mathrm{~kg}$ of concentrate and $1.5 \mathrm{~kg}$ of hay twice daily with free access to tap water. Animal experiments were approved by Ministry of Agriculture, the Environment and Rural Areas of Land Schleswig-Holstein, Germany (No. V312-72241.121-25) and were in accordance with the guidelines issued by the German authorities for care and treatments of animals (Lorz and Metzger, 2008).

The concentrate was composed of (\% of DM) 23.2 rye, 21 rapeseed extraction meal, 18 corn gluten feed, 15 milled barley grain, 12 rye bran, 4.5 beet pulp, 4 corn, and 1.05 calcium carbonate, with the addition of $7.0 \mathrm{IU}$ of vitamin $\mathrm{A}, 850 \mathrm{IU}$ of vitamin $\mathrm{D}_{3}$, and $7.5 \mathrm{mg}$ of copper (from copper-II-sulfate, pentahydrate) per kilogram of concentrate feed. Additionally, the cows re- 
ceived daily $75 \mathrm{~g}$ of mineral premix containing (\%) 41.6 calcium carbonate, 24.4 sodium chloride, 13.9 calciumsodium phosphate, 7.2 magnesium oxide, 5 sugar cane molasses, and 2 monocalcium phosphate.

After $3 \mathrm{~d}$ of recovery from surgery, 10 and $50 \mathrm{mg}$ of quercetin $/ \mathrm{kg}$ of $\mathrm{BW}$, respectively, were administered either as aglycone (quercetin dihydrate, $\geq 98 \%$ purity; Carl Roth GmbH, Karlsruhe, Germany) or as its rhamnoglucoside rutin (rutin trihydrate, $\geq 98.5 \%$ purity; Carl Roth $\mathrm{GmbH}$ ) via the rumen fistula during morning feeding. Respective amounts of quercetin or rutin were suspended in $500 \mathrm{~mL}$ of physiological saline. Saline without any addition was used as a control.

In a further trial, 2 animals received an i.v. bolus injection of $0.8 \mathrm{mg}$ of quercetin $/ \mathrm{kg}$ of $\mathrm{BW}$ dissolved in a mixture of $10 \mathrm{~mL}$ of dimethylsulfoxide (99.8\%; Carl Roth $\mathrm{GmbH}$ ) and $10 \mathrm{~mL}$ of physiological saline. The solution $(20 \mathrm{~mL})$ was directly injected via the catheter into the jugular vein through a sterile filter (Sterifix injection filter LL, $0.2-\mu \mathrm{m}$ pore size; Sarstedt AG \& Co., Nümbrecht, Germany) within 1 to 2 min. Quercetin concentration of the i.v. solution was analyzed by HPLC.

Blood samples (9 $\mathrm{mL})$ were drawn into lithiumheparinized monovettes (Sarstedt AG \& Co.) via the jugular catheter before the flavonol application (time point zero), at $0.5,1,1.5,2,2.5,3,4,6,8,12$, and 24 $\mathrm{h}$ after intraruminal application, and every $5 \mathrm{~min}$ (first hour), every $10 \mathrm{~min}$ (second hour), and at 3 and $6 \mathrm{~h}$ after i.v. bolus application. Samples were immediately centrifuged $\left(3,000 \times g, 10 \mathrm{~min}, 4^{\circ} \mathrm{C}\right)$, and 2 aliquots of plasma were stored at $-80^{\circ} \mathrm{C}$ until analysis.

\section{Analysis of Flavonols}

Flavonols were extracted from plasma as previously reported by Egert et al. (2008). The HPLC analysis of flavonols was performed as described by Hollman et al. (1996) with minor modifications. Briefly, an aliquot $(980 \mu \mathrm{L})$ of the plasma sample was spiked with $20 \mu \mathrm{L}$ of rhamnetin (internal standard, $1 \mathrm{mg} / 20 \mathrm{~mL}$ in methanol) and acidified ( $\mathrm{pH} 5)$ with $130 \mu \mathrm{L}$ of acetic acid $(0.583 \mathrm{~mol} / \mathrm{L})$. Subsequently, plasma samples were treated with $75 \mu \mathrm{L}$ of a mixture of $\beta$-glucuronidase and sulfatase (type H-1, final activities: 7,300 and $130 \mathrm{U} / \mathrm{mL}$ glucuronidase and sulfatase, respectively, Sigma-Aldrich Chemie GmbH, Taufkirchen, Germany) for cleavage of all ester bonds of glucuronidated and sulfated quercetin conjugates. Plasma samples of 2 animals obtained after intraruminal application of 50 mg of quercetin as aglycone or rutin, respectively, were additionally analyzed without enzymatic treatment (addition of $75 \mu \mathrm{L}$ of nanopure $\mathrm{H}_{2} \mathrm{O}$ ) to obtain information about unconjugated quercetin and quercetin metabolites present in plasma. After incubation for $1 \mathrm{~h}$ at $37^{\circ} \mathrm{C}, 3 \mathrm{~mL}$ of acetone was added and the sample was centrifuged at $4^{\circ} \mathrm{C}$ at $4,000 \times g$ for $45 \mathrm{~min}$. The supernatant was evaporated until dryness (partial vacuum at $45^{\circ} \mathrm{C}$, SPD2010 SpeedVac System, Thermo Fisher Scientific GmbH, Dreieich, Germany). Residues were resolved in $200 \mu \mathrm{L}$ of methanol, $77.5 \mathrm{~mL}$ of nanopure $\mathrm{H}_{2} \mathrm{O}$, and $22.5 \mu \mathrm{L}$ of $\mathrm{HCl}(10 \mathrm{~mol} / \mathrm{L})$. Thirty microliters of the final solution was injected by a cooled $\left(4^{\circ} \mathrm{C}\right)$ autosampler (Jasco, Groß-Umstadt, Germany) onto a C-18 Kromasil 100 column $(250 \times 4 \mathrm{~mm}$, particle size $5 \mu \mathrm{m}$; Jasco) guarded by a C-18 Inertsil ODS-2 pre-column (Jasco) placed in a column oven at $30^{\circ} \mathrm{C}$. The eluent $(1 \mathrm{~mL} / \mathrm{min})$ was composed of $25 \mathrm{mmol} / \mathrm{L}$ $\mathrm{NaH}_{2} \mathrm{PO}_{4}$ (pH 2.4), acetonitrile, and methanol (68:27:5, $\mathrm{vol} / \mathrm{vol} / \mathrm{vol}$ ). For postcolumn derivatization, the effluent was mixed with $\mathrm{Al}\left(\mathrm{NO}_{3}\right)_{3}(1 \mathrm{mmol} / \mathrm{L}$ in methanol containing $7.5 \%$ (vol/vol) acetic acid, flow rate 0.4 $\mathrm{mL} / \mathrm{min}$ ) in a postcolumn reactor. The fluorescence of the flavonol-aluminum complex was measured using a fluorescence detector (excitation wavelength: $422 \mathrm{~nm}$, emission wavelength: $485 \mathrm{~nm}$; FP920, Jasco). Detection limits of quercetin, isorhamnetin, and tamarixetin were $10 \mathrm{nmol} / \mathrm{L}$. Inter-analysis and inter-day variances were within 5\%. Standards were prepared with pure flavonols (Carl Roth $\mathrm{GmbH}$ ) and treated in the same manner as samples. Identification of peaks obtained in plasma samples was performed using the retention times of the pure flavonols (standards).

\section{Pharmacokinetic Calculations and Statistics}

Data presented are mean values \pm standard error of the mean. Values obtained at time point zero were subtracted from the respective values obtained after application of the test compound for each animal. With respect to the calculation of pharmacokinetic parameters, we determined maximum plasma concentration $\left(\mathbf{c}_{\max }\right)$, time to achieve maximum plasma concentration $\left(\mathbf{t}_{\max }\right.$; GraphPadPrism version 4.01, GraphPad Software Inc., San Diego, CA), and the area under the curve (AUC) according to the trapezoidal rule. Relative and absolute bioavailabilities were calculated using the AUC according to Pfeifer et al. (1995). For comparison of pharmacokinetic parameters after quercetin and rutin application $(50 \mathrm{mg} / \mathrm{kg}$ of BW), respectively, the paired $t$-test was used. A $P$-value $<0.05$ was considered to be significant. Further pharmacokinetic parameters such as the terminal elimination half-life were not calculated because plasma concentrations of individual cows between 8 and $24 \mathrm{~h}$ after application of test substances were very low, and intervals between plasma sampling were too large to allow an accurate calculation of these parameters. 


\section{RESULTS}

Plasma flavonol concentrations in samples of 2 animals that received $50 \mathrm{mg}$ of quercetin $/ \mathrm{kg}$ of BW as rutin intraruminally, as well as samples obtained from the animals dosed with $0.8 \mathrm{mg}$ of quercetin $/ \mathrm{kg}$ of $\mathrm{BW}$ i.v., were determined with and without a mixture of $\beta$-glucuronidase and sulfatase. Only nonconjugated flavonols can be measured without enzymatic treatment, whereas those flavonols present as conjugates (glucuronides, sulfates) are additionally assessed after enzymatic treatment (total flavonols $=$ sum of nonconjugated and conjugated quercetin and quercetin derivatives with an intact flavonol structure). Although the area under the plasma concentration-time curve after intraruminal application was increased by about $90 \%$ after enzymatic treatment (Figure 2), the measurable flavonol content in those samples obtained after i.v. application was not substantially increased by the glucuronidase and sulfatase treatment (results not shown). Based on these findings, further results concerning plasma concentrations of quercetin and its derivatives were obtained after enzymatic treatment of plasma samples.

The plasma concentration-time curve of total flavonols and single flavonols (quercetin, isorhamnetin, tamarixetin, kaempferol) after i.v. application are shown in Figure 3a. Expressed as a percentage of the AUC of total flavonols, quercetin was the main metabolite found in plasma ( $57 \%$ of total flavonols), followed by isorhamnetin $(35.7 \%)$, tamarixetin $(29.2 \%)$, and kaempferol $(12.3 \%)$. Whereas the plasma concentrations of total and individual flavonols decreased rapidly with time, the relative contributions of quercetin and quercetin metabolites (isorhamnetin, tamarixetin, kaempferol) to total flavonols changed over time. The relative concentration of quercetin decreased continuously from 5 to $50 \mathrm{~min}$ from 80 to $\sim 35 \%$, and the sum of its metabolites concurrently increased from 20 to $70 \%$ (Figure 3b).

Intraruminal application of physiological saline without any addition (control) resulted in a plasma concentration of quercetin close to or below the detection limit over the whole 24-h sampling period (Figure 4a). Quercetin derivatives (isorhamnetin, tamarixetin, and kaempferol) were not detected. After intraruminal administration of $10 \mathrm{mg}$ of quercetin $/ \mathrm{kg}$ of $\mathrm{BW}$, the concentration of total flavonols in plasma was close to the detection limit at most time points (Figure 4a). At this dosage of quercetin aglycone, the concentrations of quercetin derivatives were always below the detection limit (data not shown). At $50 \mathrm{mg}$ of quercetin $/ \mathrm{kg}$ of $\mathrm{BW}$, a maximum plasma concentration of total flavonols was detected after 30 min (Figure 4a, Table 1). In addition to quercetin, only traces of kaempferol were found (data not shown). The absolute bioavailability

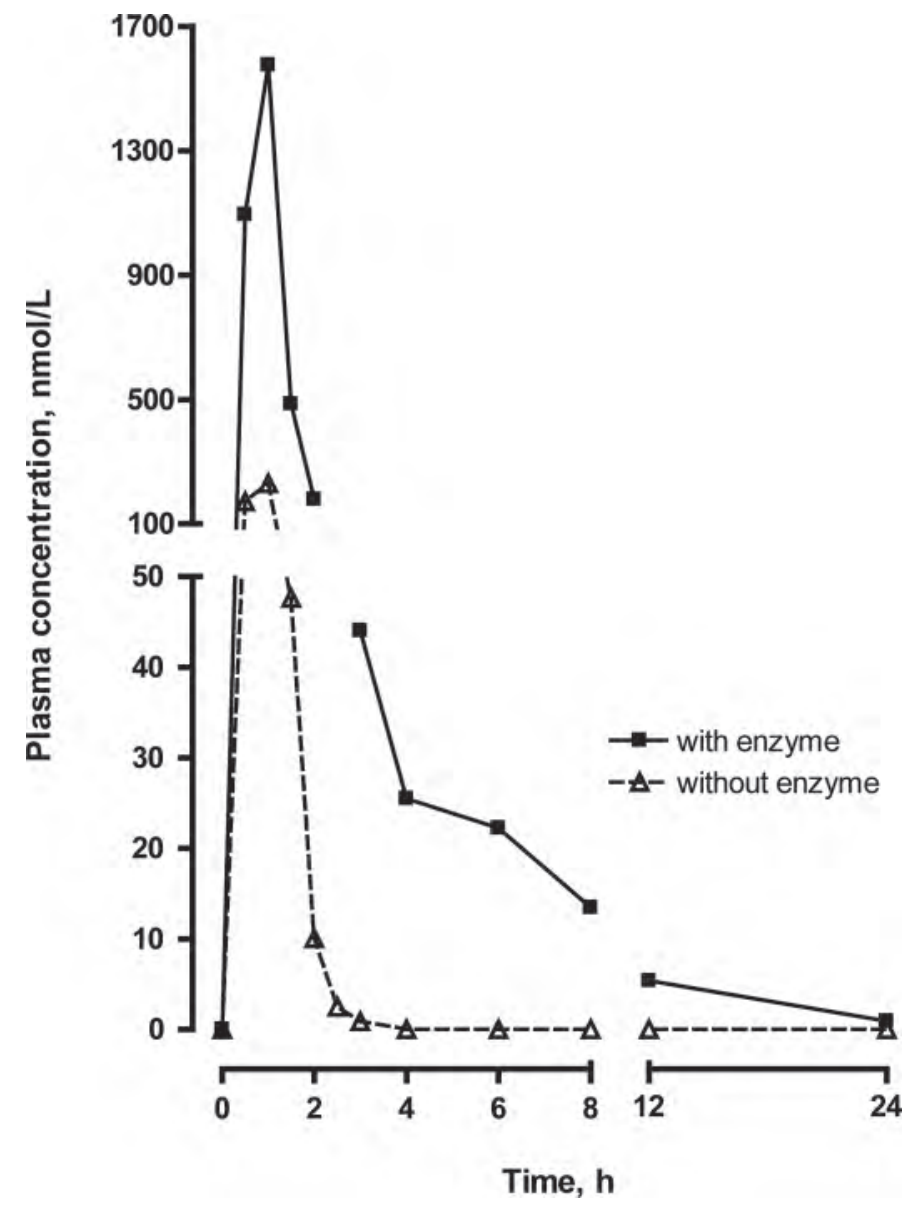

Figure 2. Plasma concentration-time curve of total flavonols after intraruminal application of $50 \mathrm{mg}$ of quercetin $/ \mathrm{kg}$ of $\mathrm{BW}$ as rutin. Plasma samples were analyzed with and without $\beta$-glucuronidase/sulfatase treatment. Values are means from 2 animals.

of quercetin after intraruminal application of $50 \mathrm{mg}$ of quercetin $/ \mathrm{kg}$ of BW was calculated to be $0.1 \%$.

In contrast to the application of the quercetin aglycone, the intraruminal administration of $10 \mathrm{mg}$ of quercetin $/ \mathrm{kg}$ of $\mathrm{BW}$ as rutin resulted in measurable concentrations of flavonols in plasma, with a maximal concentration obtained after $30 \mathrm{~min}$ (Figure 4b). Over the whole sampling period, quercetin metabolites, however, were present at low concentrations, amounting to $<1 \%$ of total flavonols. The concentration of total flavonols decreased below the detection limit within $8 \mathrm{~h}$.

After application of the higher rutin dose $(50 \mathrm{mg}$ of quercetin $/ \mathrm{kg}$ of $\mathrm{BW}$ ), the maximal plasma concentration was observed after $42 \mathrm{~min}$ and was about 10 times higher (about $1 \mu \mathrm{mol} / \mathrm{L}$ ) compared with the high quercetin dosage $(0.09 \mu \mathrm{mol} / \mathrm{L}$; Figure $4 \mathrm{~b}$, Table 1$)$. Concentrations of the 3 quercetin derivatives amounted to $12.5 \%$ of total flavonols at $c_{\max }$ and declined below detection limit $2 \mathrm{~h}$ after application (data not shown). 


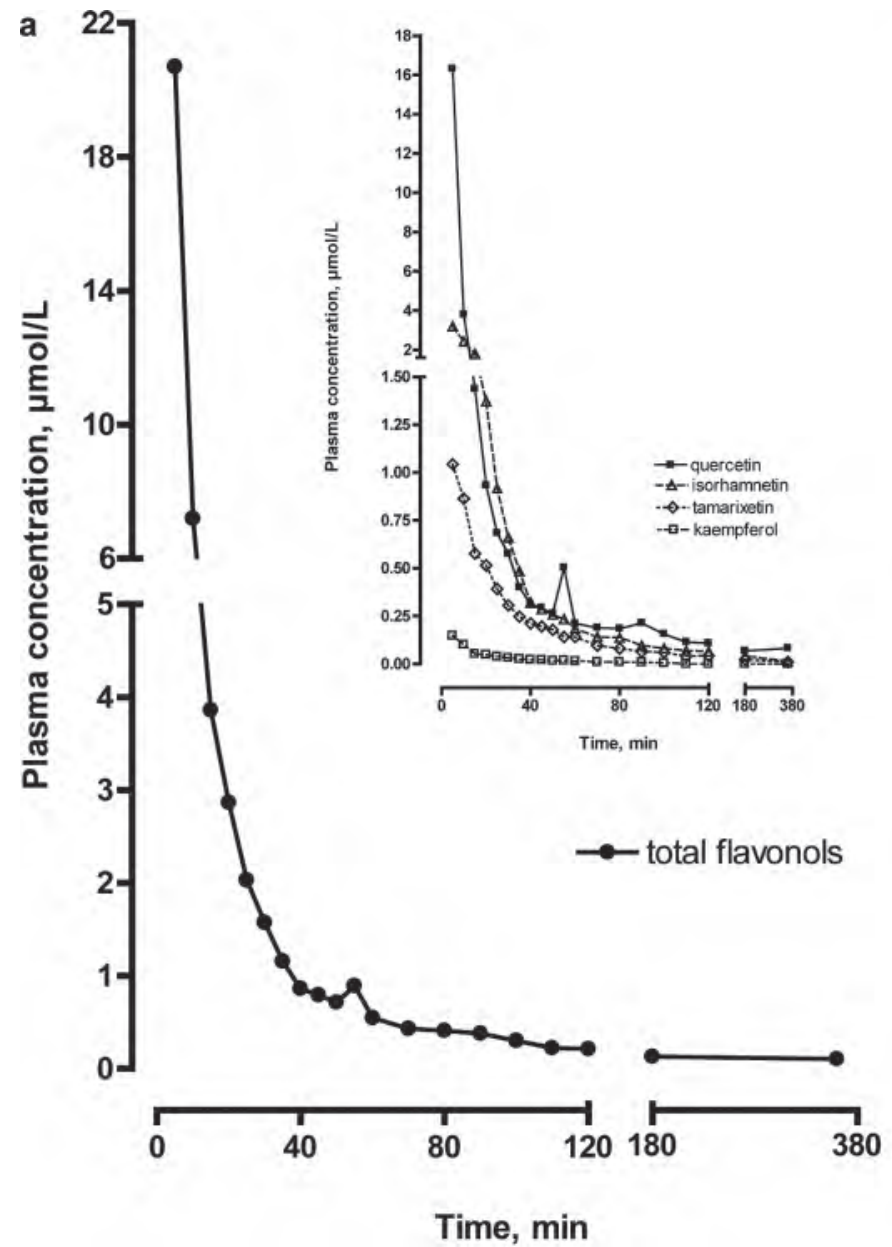

b

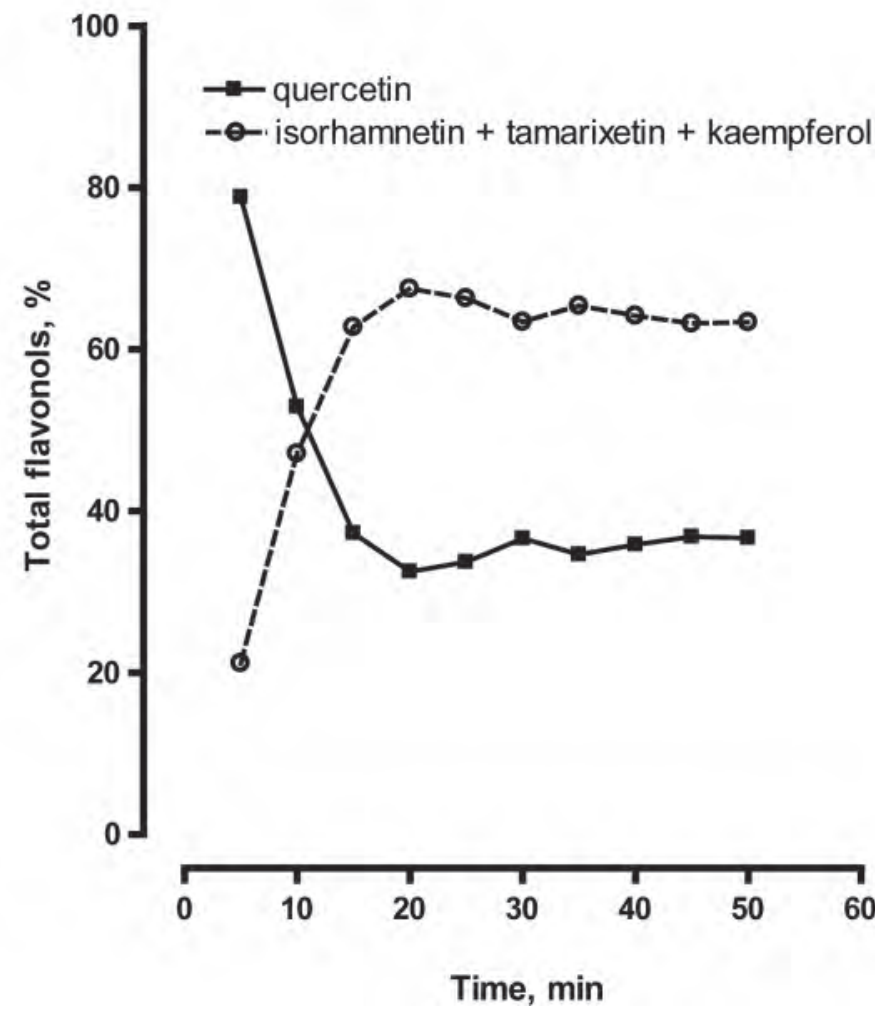

Figure 3. (a) Plasma concentration-time curve of total flavonols after i.v. application of $0.8 \mathrm{mg}$ of quercetin aglycone $/ \mathrm{kg}$ of BW. Inset: Plasma concentration-time curves of quercetin and its derivatives (isorhamnetin, tamarixetin, kaempferol). Values are means, $\mathrm{n}=2$. (b) Percentages of quercetin and metabolites with intact flavonol structure (isorhamnetin, tamarixetin, kaempferol), respectively, from 5 to 50 min after i.v. application of $0.8 \mathrm{mg}$ of quercetin $/ \mathrm{kg}$ of $\mathrm{BW}$. Values are means, $\mathrm{n}=2$.

The relative bioavailability of quercetin after the intraruminal administration of rutin at the higher dose (compared with the respective dose of quercetin aglycone) was $767.3 \%$, whereas the absolute bioavailability was calculated to be $0.5 \%$. After application of the high quercetin and rutin dosages, concentrations of total flavonols decreased below the detection limit within $24 \mathrm{~h}$.

\section{DISCUSSION}

During the last $10 \mathrm{yr}$, many studies have investigated possible effects of quercetin, such as antioxidant and antiinflammatory capabilities and effects on gene expression and enzyme systems, in monogastric species including humans (Erlund, 2004; Williamson and Manach, 2005). Based on these findings, similar effects can be assumed in ruminants, in which the early lactation phase in dairy cows would be most interesting because this phase is often accompanied by metabolic disturbances due to insufficient feed intake and massive mobilization of body reserves (Ingvartsen et al., 2006).

Knowledge on the bioavailability of quercetin is required to determine their potential to exert biological effects, especially with respect to the interpretation of data obtained from in vitro experiments. Hence, the bioavailability of quercetin from quercetin aglycone and quercetin glycosides has been investigated in different monogastric species (Manach et al., 1997; Ader et al., 2000; Erlund et al., 2000). However, because of marked differences in the gastrointestinal tract of ruminants compared with monogastric species, the bioavailability of quercetin in cattle cannot be predicted from those data. Therefore, the present study was performed to determine for the first time the bioavailability of quercetin in cattle after intraruminal application of quercetin as either the aglycone or its glucorhamnoside rutin. 
a

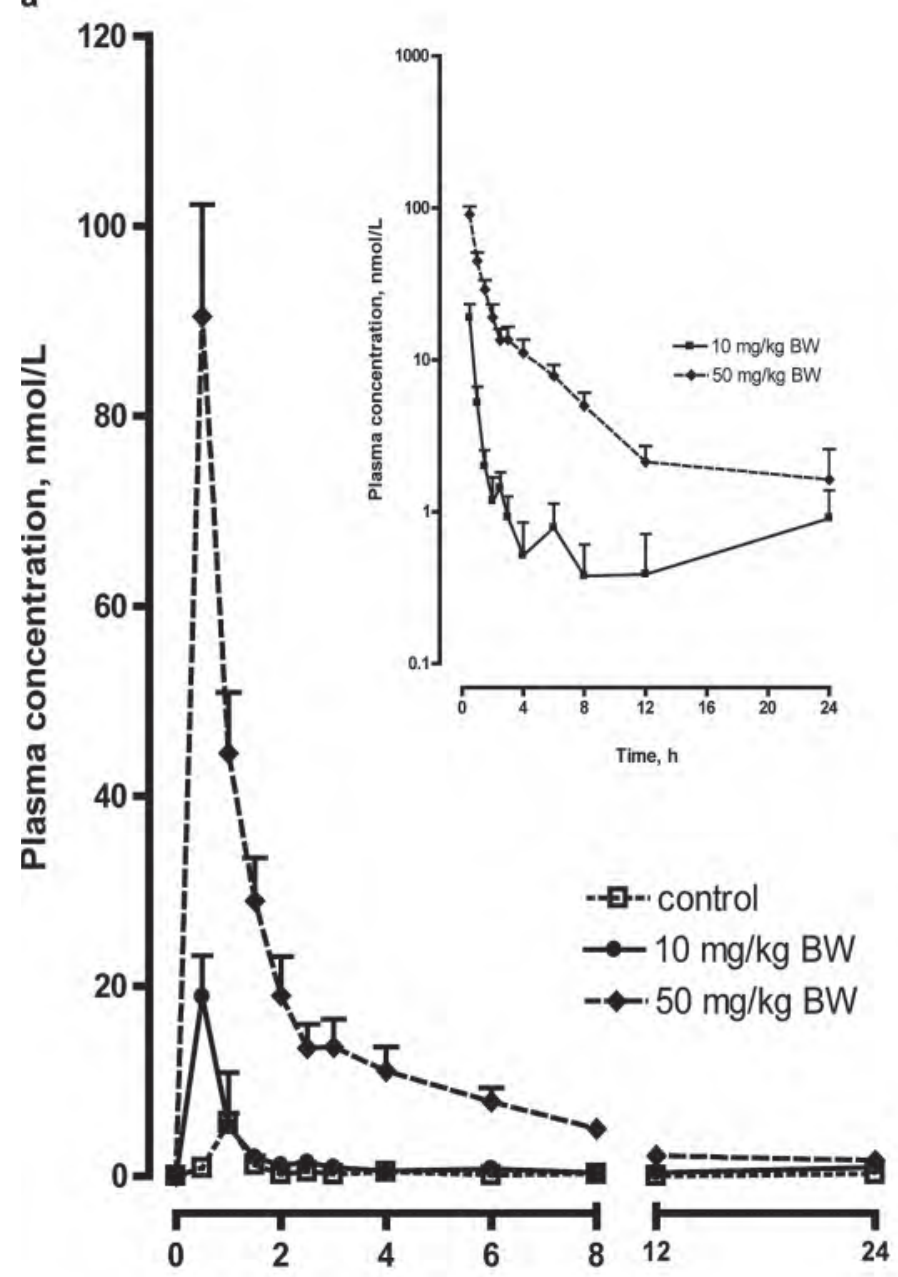

b 1200

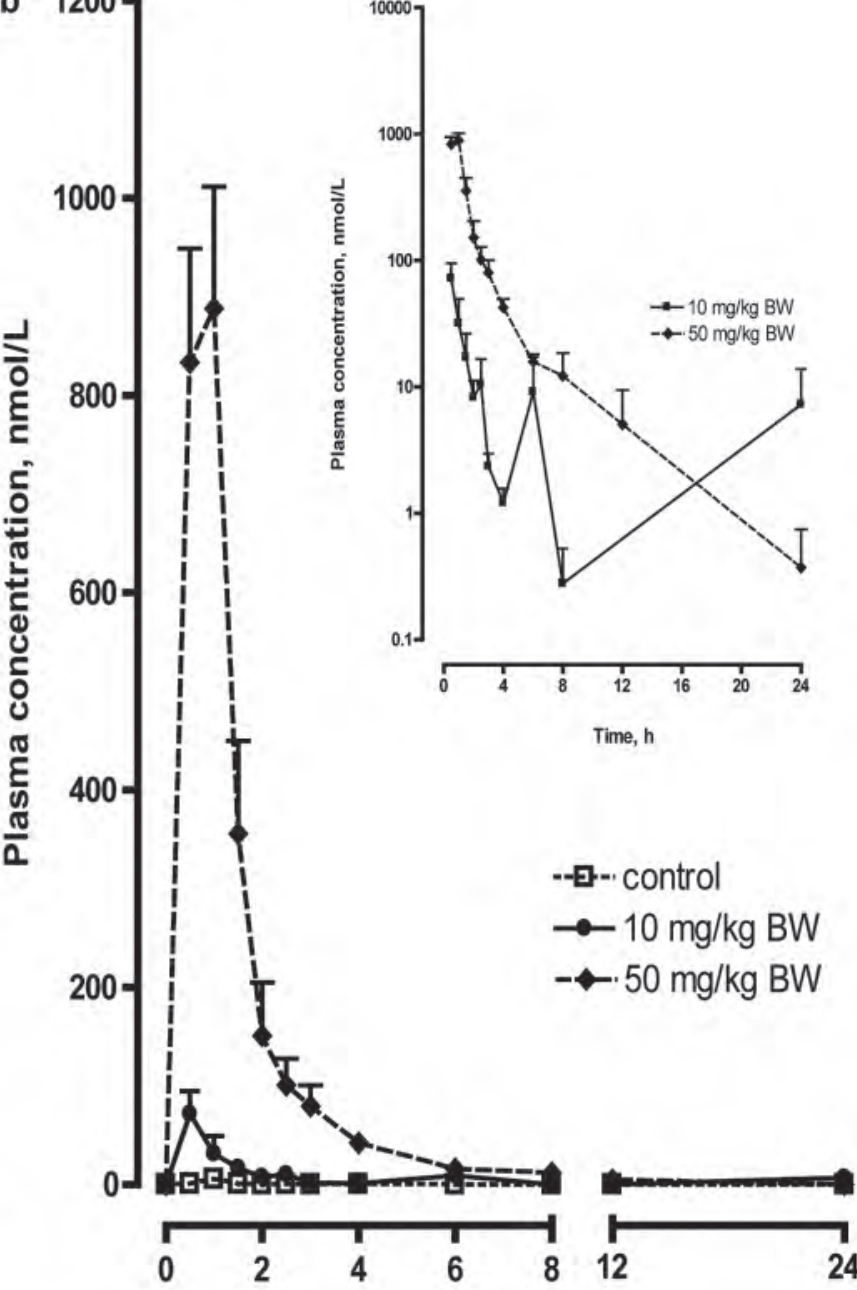

Time, $\mathrm{h}$

Figure 4. (a) Plasma concentration-time curve of total flavonols after intraruminal application of 0, 10, and $50 \mathrm{mg}$ of quercetin/kg of BW as quercetin aglycone. Values are means $\pm \mathrm{SEM}, \mathrm{n}=5$ for 10 and $50 \mathrm{mg} / \mathrm{kg} \mathrm{BW} ; \mathrm{n}=4$ for control. Inset: Plasma concentration-time curves of total flavonols after intraruminal application of 10 and $50 \mathrm{mg}$ of quercetin $/ \mathrm{kg}$ of BW as quercetin aglycone; y-axis is represented by logscale. Values are means \pm SEM, $\mathrm{n}=5$. (b) Plasma concentration-time curve of total flavonols after intraruminal application of 0 , 10, and 50 $\mathrm{mg}$ of quercetin $/ \mathrm{kg}$ of BW as rutin trihydrate. Values are means \pm SEM, $\mathrm{n}=5$, for 10 and $50 \mathrm{mg} / \mathrm{kg}$ of BW; $\mathrm{n}=4$ for control. Inset: Plasma concentration-time curves of total flavonols after intraruminal application of 10 and $50 \mathrm{mg}$ of quercetin/ $\mathrm{kg}$ of BW as rutin; y-axis is represented by $\log$-scale. Values are means $\pm \mathrm{SEM}, \mathrm{n}=5$.

Irrespective of the dose applied, the results obtained clearly show plasma concentrations of quercetin more than 10-fold higher after administration of rutin compared with quercetin aglycone. This finding is in striking contrast to results obtained in monogastric species. In humans, pigs, and rats, bioavailability of quercetin from rutin is much lower compared with that from application of isomolar amounts of quercetin aglycone (Manach et al., 1997; Erlund et al., 2000; Cermak et al., 2003). Interestingly, similar results were obtained in a parallel experiment in dairy cows after intraduodenal application of quercetin and rutin, respectively (Gohlke et al., 2011).

Findings in monogastric species showed that quercetin from rutin is not deglycosylated until it has reached the colon because of a lack of rhamnosidase activity in the small intestine (Bokkenheuser et al., 1987; Cermak et al., 2003). Hence, compared with the application of quercetin aglycone, the plasma appearance of quercetin and quercetin derivatives after oral application of rutin is delayed and, because of substantial microbial degradation and possibly lower absorption rates in the 
Table 1. Pharmacokinetic parameters (means \pm SEM; $\mathrm{n}=5$ ) and relative bioavailability after intraruminal application of $50 \mathrm{mg}$ of quercetin $/ \mathrm{kg}$ of BW as quercetin aglycone or rutin

\begin{tabular}{|c|c|c|}
\hline Item & Quercetin & Rutin \\
\hline $\begin{array}{l}\mathrm{c}_{\max },{ }_{2}^{1} \mu \mathrm{mol} / \mathrm{L} \\
\mathrm{t}_{\max },{ }_{\min } \\
\text { AUC }_{\text {Total }},{ }^{3} \min \times \mu \mathrm{mol} / \mathrm{L} \\
\text { Relative bioavailability, }{ }^{4} \%\end{array}$ & $\begin{aligned} & 0.09 \pm 0.01^{\mathrm{a}} \\
& 30.0 \pm 0.0^{\mathrm{a}} \\
& 10.94 \pm 1.76^{\mathrm{a}} \\
& 100\end{aligned}$ & $\begin{aligned} 1.0 & \pm 0.10^{\mathrm{b}} \\
42.0 & \pm 7.3^{\mathrm{a}} \\
83.96 & \pm 9.35^{\mathrm{b}} \\
767.3 & \end{aligned}$ \\
\hline
\end{tabular}

${ }^{\mathrm{a}, \mathrm{b}}$ Means in a row without a common letter differ significantly, $P<$ 0.05 .

${ }^{1} \mathrm{c}_{\max }=$ maximum plasma concentration of total flavonols.

${ }^{2} t_{\max }=$ time between administration of the test compound and the appearance of $\mathrm{c}_{\max }$.

${ }^{3} \mathrm{AUC}_{\text {Total }}=$ area under the plasma concentration-time curve from 0 to 1,440 min for the sum of quercetin and its metabolites (isorhamnetin, tamarixetin, and kaempferol).

${ }^{4}$ Relative bioavailability of total flavonols from rutin compared with quercetin calculated via mean $\mathrm{AUC}_{\text {Total }}$.

large intestine, the concentrations reached in plasma are much lower (Erlund et al., 2000; Cermak et al., 2003). In vitro experiments with ruminal and fecal inocula have found complete microbial degradation of quercetin (Cheng et al., 1969; Lin et al., 2003). In regard to our results, the low plasma concentrations of quercetin and quercetin derivatives after application of the aglycone might be due to rapid and extensive microbial degradation of the quercetin applied. This might also explain the very low systemic availability of quercetin $(<1 \%)$ after intraruminal application of quercetin aglycone in our study. In monogastric species, bioavailability of quercetin after oral application of a similar dose of quercetin aglycone was calculated to be $4 \%$ in rats (Chen et al., 2005), 17\% in pigs (Ader et al., 2000), and 59\% in dogs (Reinboth et al., 2010).

After intraruminal application of rutin, the sugar moiety is likely hydrolyzed by rhamnosidases before absorption occurs. Cleavage of the sugar moiety from rutin might be a prerequisite for microbial degradation of the aglycone. Because much higher plasma concentrations of quercetin and quercetin derivatives were found after application of rutin compared with quercetin aglycone, we assume some kind of protection from microbial degradation of quercetin in the rumen when applied as rutin, resulting in a higher bioavailability of quercetin. Maximum plasma concentrations of total flavonols from rutin, as found in our study, are comparable to those obtained in monogastric species after application of an equimolar amount of quercetin aglycone (Ader et al., 2000; Egert et al., 2008).

The decline in plasma concentration is much more rapid in cows compared with monogastric species. Because the rapid decline is principally attributable to tissue distribution and elimination from circulation, the differences between our findings and those reported in monogastric species are most likely due to species differences in tissue distribution, elimination, or both.

The early peak plasma concentration of total flavonols after 30 to 45 min indicates that absorption, irrespective of the quercetin form and dose administered, occurred rapidly after intraruminal application. Results are in contrast to findings in monogastric species, in which the $t_{\max }$ of quercetin in plasma after application of the aglycone was reached between 2 and $4 \mathrm{~h}$ in pigs and humans (Erlund et al., 2000; Cermak et al., 2003; Egert et al., 2008). After administration of rutin, the $\mathrm{t}_{\max }$ of total plasma quercetin was reached between 6.5 and $7.5 \mathrm{~h}$ in humans (Erlund et al., 2000). In monogastric species, quercetin aglycone is absorbed in the small intestine (Crespy et al., 1999), whereas absorption of quercetin from rutin is limited to the large intestine, as described above. With respect to the early appearance of peak plasma concentration in our study, Lundh et al. (1990) found maximum plasma concentrations of the isoflavones formononetin and daidzein (including the metabolite equol) within $1 \mathrm{~h}$ after oral administration of formononetin and daidzein to cows and assumed that quercetin might be absorbed already from the rumen.

After intraruminal application, quercetin was the main metabolite in plasma, irrespective of the form and dose applied. Plasma concentrations of methylated derivatives (isorhamnetin, tamarixetin) and of kaempferol were always within the range or below the detection limit, except when the high rutin dose was applied. Results are in accordance with findings of Ader et al. (2000) and Reinboth et al. (2010), who also found quercetin as the main plasma metabolite in pigs and dogs, respectively, after administration of quercetin aglycone. In contrast, Manach et al. $(1996,1997)$ found isorhamnetin to be the main metabolite in plasma of rats after application of quercetin and rutin, respectively.

Comparison of flavonol plasma concentrations in samples treated with and without $\beta$-glucuronidase and sulfatase showed that quercetin and its metabolites mainly appear as conjugates in plasma after intraruminal administration. These findings are in accordance with those obtained by Ader et al. (2000). In contrast, Bieger et al. (2008) and Cermak et al. (2003) did not find any free quercetin in plasma of pigs without enzymatic treatment of plasma samples. In agreement with our results, Lundh et al. (1990) reported that conjugated isoflavone metabolites represented more than $90 \%$ of circulating forms in plasma of cows. Moreover, conjugation occurred rapidly with maximum plasma concentration of conjugated forms within $1 \mathrm{~h}$ after administration (Lundh et al., 1990). The low plasma concentrations of unconjugated quercetin and quercetin derivatives suggest extensive conjugation by phase II enzymes in liver and intestinal mucosa (Boutin et al., 
1993; Crespy et al., 1999; Walle et al., 1999). According to the results of Reinboth et al. (2010), intensive conjugation of quercetin during absorption could explain a low degree of methylation after intraruminal administration of quercetin and rutin.

Knowledge is lacking on the conversion of quercetin to kaempferol (also found in plasma) in both ruminants and monogastric species. Indeed, kaempferol was detected in porcine plasma by Ader et al. (2000) and Cermak et al. (2003) after application of quercetin and rutin, respectively. However, its appearance was attributed to an impurity of the quercetin preparation used in those studies. In contrast, in our study, kaempferol found after intraruminal administration was not due to an impurity of the quercetin and rutin applied. Thus, kaempferol was most likely formed by microbial dehydroxylation at position C-3' within the rumen (Heider and Fuchs, 1997).

After i.v. application of quercetin, kaempferol (as well as methylated quercetin derivative) was detected in plasma samples, being the second most abundant metabolite after quercetin. Ader et al. (2000) reported similar findings after i.v. application of quercetin in pigs. With respect to methylated quercetin derivatives in plasma, the concentration of isorhamnetin was higher than that of tamarixetin. Similar findings were reported by Ader et al. (2000) in pigs, where the concentration of isorhamnetin was more than twice that of tamarixetin. Ader et al. (2000) assumed that postabsorptive methylation of quercetin at position C-3' (isorhamnetin) was more likely than methylation at C-4' (tamarixetin). Tilgmann and Ulmanen (1996) reported similar findings for the methylation of catechols. Whereas methylation of quercetin absorbed might occur in the liver (Ader et al., 2000; Reinboth et al., 2010), the origin of kaempferol after i.v. application of quercetin is difficult to explain. Again, contamination of the quercetin applied can be excluded. Thus, we assume that dehydroxylation of quercetin to kaempferol, which early appeared in plasma after i.v. application of quercetin, must have occurred in the liver. In this context, Saulter et al. (2005) determined that a hepatic cytochrome reductase is capable of dehydroxylating the amidoxime furamidine. However, to date, no clear evidence exists for dehydroxylation capabilities of the liver toward quercetin.

\section{CONCLUSIONS}

The results obtained in the present study indicate that the bioavailability of quercetin, including methylated derivatives with an intact flavonol structure, is significantly higher after intraruminal application of rutin compared with quercetin aglycone. This is in contrast to findings in monogastric species such as rats, dogs, pigs, and humans. The differences can be explained by the different structures of the gastrointestinal tract and various sites of absorption between ruminants and monogastric species. Similar to findings in monogastric species, flavonols in plasma are mainly present as conjugated forms. Regarding the low bioavailability of quercetin in addition to the very rapid decline of plasma concentrations after reaching $c_{\max }$, the question arises whether biological effects of quercetin (e.g., an influence on energy metabolism, oxidative stress, or gene expression) can be expected. This question cannot be answered based on the results presented here. Only experiments focusing on biological effects of quercetin in cows can eventually yield this information. Finally, it should be kept in mind that feed intake (and in turn, passage of ingesta) is considerably higher in (highyielding) dairy cows compared with the nonlactating cows used in our study. This might influence metabolism and absorption of quercetin irrespective of the site of absorption (rumen or small intestine). Thus, the present data should be regarded as the first information on bioavailability of quercetin in ruminants. Specific factors such as the influence of the performance level must be addressed in future studies.

\section{ACKNOWLEDGMENTS}

The authors are grateful to Petra Schulz and Maike Jürgensen (both of Institute of Animal Nutrition and Physiology, Christian-Albrechts-University of Kiel, Kiel, Germany) for excellent technical assistance. This work was financially supported by the Federal Ministry of Education and Research, Germany (grant no. 0315538A).

\section{REFERENCES}

Ader, P., A. Wessmann, and S. Wolffram. 2000. Bioavailability and metabolism of the flavonol quercetin in the pig. Free Radic. Biol. Med. 28:1056-1067.

Besle, J. M., D. Viala, B. Martin, P. Pradel, B. Meunier, J. L. Berdagué, D. Fraisse, J. L. Lamaison, and J. B. Coulon. 2010. Ultraviolet-absorbing compounds in milk are related to forage polyphenols. J. Dairy Sci. 93:2846-2856.

Bieger, J., R. Cermak, R. Blank, V. C. J. de Boer, P. C. H. Hollman, J. Kamphues, and S. Wolffram. 2008. Tissue distribution of quercetin in pigs after long-term dietary supplementation. J. Nutr. 138:1417-1420.

Blaut, M., L. Schoefer, and A. Braune. 2003. Transformation of flavonoids by intestinal microorganisms. Int. J. Vitam. Nutr. Res. 73:79-87.

Bokkenheuser, V. D., C. H. L. Shackleton, and J. Winter. 1987. Hydrolysis of dietary flavonoid glycosides by strains of intestinal Bacteroides from humans. Biochem. J. 248:953-956.

Bors, W., W. Heller, C. Michel, and M. Saran. 1990. Flavonoids as antioxidants: Determination of radical-scavenging efficiencies. Methods Enzymol. 186:343-355. 
Boutin, J. A., F. Meunier, P.-H. Lambert, P. Hennig, D. Bertin, B. Serkiz, and J.-P. Volland. 1993. In vivo and in vitro glucuronidation of the flavonoid diosmetin in rats. Drug Metab. Dispos. 21:1157-1166.

Broudiscou, L. P., Y. Papon, and A. F. Broudiscou. 2000. Effects of dry plant extracts on fermentation and methanogenesis in continuous culture of rumen microbes. Anim. Feed Sci. Technol. 87:263-277.

Cermak, R., S. Landgraf, and S. Wolffram. 2003. The bioavailability of quercetin in pigs depends on the glycoside moiety and on dietary factors. J. Nutr. 133:2802-2807.

Chen, X., O. Q. P. Yin, Z. Zuo, and M. S. S. Chow. 2005. Pharmacokinetics and modeling of quercetin and metabolites. Pharm. Res. 22:892-901.

Cheng, K.-J., G. A. Jones, F. J. Simpson, and M. P. Bryant. 1969. Isolation and identification of rumen bacteria capable of anaerobic rutin degradation. Can. J. Microbiol. 15:1365-1371.

Crespy, V., C. Morand, C. Manach, C. Besson, C. Démigné, and C. Rémésy. 1999. Part of quercetin absorbed in the small intestine is conjugated and further secreted in the intestinal lumen. Am. J. Physiol. 277:G120-G126.

Crozier, A., I. B. Jaganath, and M. N. Clifford. 2006. Phenols, polyphenols and tannins: An overview. Pages 1-24 in Plant Secondary Metabolites: Occurrence, Structure and Role in the Human Diet. Blackwell Publishing Ltd., Oxford, UK.

Duske, K., H. M. Hammon, A. K. Langhof, O. Bellmann, B. Losand, K. Nürnberg, G. Nürnberg, H. Sauerwein, H. M. Seyfert, and C. C. Metges. 2009. Metabolism and lactation performance in dairy cows fed a diet containing rumen-protected fat during the last twelve weeks of gestation. J. Dairy Sci. 92:1670-1684.

Egert, S., S. Wolffram, A. Bosy-Westphal, C. Boesch-Saadatmandi, A. E. Wagner, J. Frank, G. Rimbach, and M. J. Mueller. 2008. Daily quercetin supplementation dose-dependently increases plasma quercetin concentrations in healthy humans. J. Nutr. 138:16151621.

Erlund, I. 2004. Review of the flavonoids quercetin, hesperetin, and naringenin. Dietary sources, bioactivities, bioavailability, and epidemiology. Nutr. Res. 24:851-874.

Erlund, I., T. Kosonen, G. Alfthan, J. Mäenpää, K. Perttunen, J. Kenraali, J. Parantainen, and A. Aro. 2000. Pharmacokinetics of quercetin from quercetin aglycone and rutin in healthy volunteers. Eur. J. Clin. Pharmacol. 56:545-553.

Gasparin, F. R. S., F. L. Spitzner, E. L. Ishii-Iwamoto, A. Bracht, and J. Constantin. 2003. Actions of quercetin on gluconeogenesis and glycolysis in rat liver. Xenobiotica 33:903-911.

Gee, J. M., M. S. DuPont, A. J. Day, G. W. Plumb, G. Williamson, and I. T. Johnson. 2000. Intestinal transport of quercetin glycosides in rats involves both deglycosylation and interaction with the hexose transport pathway. J. Nutr. 130:2765-2771.

Gohlke, A., C. J. Ingelmann, G. Nürnberg, S. Wolffram, and C. C. Metges. 2011. Bioavailability of duodenal administered flavonoids and acute effects on milk yield in high-yielding German-Holstein cows: Preliminary results. 3rd COST Feed for Health Conference Copenhagen, Denmark. Accessed Jun. 11, 2012. http://www.feedforhealth.org/default.asp?ZNT=S0T1O856.

Hammon, H. M., G. Stürmer, F. Schneider, A. Tuchscherer, H. Blum, T. Engelhard, A. Genzel, R. Staufenbiel, and W. Kanitz. 2009. Performance and metabolic and endocrine changes with emphasis on glucose metabolism in high-yielding dairy cows with high and low fat content in liver after calving. J. Dairy Sci. 92:1554-1566.

Heider, J., and G. Fuchs. 1997. Anaerobic metabolism of aromatic compounds. Eur. J. Biochem. 243:577-596.

Hollman, P. C. H., M. N. C. P. Bijsman, Y. van Gameren, E. P. J. Cnossen, J. H. M. de Vries, and M. B. Katan. 1999. The sugar moiety is a major determinant of the absorption of dietary flavonoid glycosides in man. Free Radic. Res. 31:569-573.

Hollman, P. C. H., J. M. P. van Trijp, and M. N. C. P. Bijsman. 1996. Fluorescence detection of flavonols in HPLC by postcolumn chelation with aluminum. Anal. Chem. 68:3511-3515.
Ingvartsen, K. L., R. J. Dewhurst, and N. C. Friggens. 2006. On the relationship between lactational performance and health: Is it yield or metabolic imbalance that cause production diseases in dairy cattle? A position paper. Livest. Prod. Sci. 83:277-308.

Kobayashi, Y., M. Miyazawa, A. Kamel, K. Abe, and T. Kojima. 2010. Ameliorative effects of mulberry (Morus alba L.) leaves on hyperlipidemia in rats fed a high-fat diet: Induction of fatty acid oxidation, inhibition of lipogenesis, and suppression of oxidative stress. Biosci. Biotechnol. Biochem. 74:2385-2395.

Kühnau, J. 1976. The flavonoids. A class of semi-essential food components: Their role in human nutrition. World Rev. Nutr. Diet. 24:117-191.

Labib, S., A. Erb, M. Kraus, T. Wickert, and E. Richling. 2004. The pig caecum model: A suitable tool to study the intestinal metabolism of flavonoids. Mol. Nutr. Food Res. 48:326-332.

Lin, Y.-T., S.-L. Hsiu, Y.-C. Hou, H.-Y. Chen, and P.-D. L. Chao. 2003. Degradation of flavonoid aglycones by rabbit, rat and human fecal flora. Biol. Pharm. Bull. 26:747-751.

Lorz, A., and E. Metzger. 2008. Tierschutzgesetz: Tierschutzgesetz mit Allgemeiner Verwaltungsvorschrift, Rechtsverordnungen und Europäische Übereinkommen; Kommentar. 6th ed. C. H. Beck Verlag Munich, Germany.

Lundh, T. J.-H., H. I. Pettersson, and K. A. Martinsson. 1990. Comparative levels of free and conjugated plant estrogens in blood plasma of sheep and cattle fed estrogenic silage. J. Agric. Food Chem. 38:1530-1534.

Manach, C., C. Morand, C. Démigné, O. Texier, F. Régérat, and C. Rémésy. 1997. Bioavailability of rutin and quercetin in rats. FEBS Lett. 409:12-16.

Manach, C., O. Texier, F. Régérat, G. Agullo, C. Démigné, and C. Rémésy. 1996. Dietary quercetin is recovered in rat plasma as conjugated derivatives of isorhamnetin and quercetin. J. Nutr. Biochem. 7:375-380.

Middleton, E., C. Kandaswami, and T. C. Theoharides. 2000. The effects of plant flavonoids on mammalian cells: Implications for inflammation, heart disease, and cancer. Pharmacol. Rev. 52:673751

Morand, C., V. Crespy, C. Manach, C. Besson, C. Démigné, and C Rémésy. 1998. Plasma metabolites of quercetin and their antioxidant properties. Am. J. Physiol. 275:R212-R219.

Pfeifer, S., P. Pflegel, and H.-H. Borchert. 1995. Pharmakokinetische Analyse. Page 135 in Biopharmazie: Pharmakokinetik-Bioverfügbarkeit-Biotransformation. 3rd ed. Ullstein/Mosby GmbH \& Co. KG, Berlin/Wiesbaden, Germany.

Reinboth, M., S. Wolffram, G. Abraham, F. R. Ungemach, and R. Cermak. 2010. Oral bioavailability of quercetin from different quercetin glycosides in dogs. Br. J. Nutr. 104:198-203.

Saulter, J. Y., J. R. Kurian, L. A. Trepanier, R. R. Tidwell, A. S. Bridges, D. W. Boykin, C. E. Stephens, M. Anbazhagan, and J. E. Hall. 2005. Unusual dehydroxylation of antimicrobial amidoxime prodrugs by cytochrome b5 and NADH cytochrome b5 reductase. Drug Metab. Dispos. 33:1886-1893.

Tilgmann, C., and I. Ulmanen. 1996. Purification methods of mammalian catechol-O-methyltransferases. J. Chromatogr. B Biomed. Appl. 684:147-161.

Walle, U. K., A. Galijatovic, and T. Walle. 1999. Transport of the flavonoid chrysin and its conjugated metabolites by the human intestinal cell line Caco-2. Biochem. Pharmacol. 58:431-438.

Williamson, G., and C. Manach. 2005. Bioavailability and bioefficacy of polyphenols in humans. II. Review of 93 intervention studies. Am. J. Clin. Nutr. 81:243S-255S.

Wolffram, S., M. Blöck, and P. Ader. 2002. Quercetin-3-glucoside is transported by the glucose carrier SGLT1 across the brush border membrane of rat small intestine. J. Nutr. 132:630-635. 